\title{
Preliminary study of haplotypes linked to the rare cystic fibrosis E1104X mutation
}

\author{
S Oueslati, S Hadj Fredj, R Belhaj, H Siala, A Bibi, T Messaoud \\ Biochemistry Laboratory, Research Laboratory "Haemoglobinopathies and Cystic Fibrosis, LROOSPO3", \\ Children's Hospital, Tunis, Tunisia
}

Received: February 1, 2012

Accepted after revision: August 29, 2012

\begin{abstract}
The analysis of some extra- and intragenic markers within or closely linked to the cystic fibrosis transmembrane regulator $(C F T R)$ gene is useful as a molecular method in clinical linkage analysis. Indeed, knowing that the molecular basis of cystic fibrosis (CF) is highly heterogeneous in our population, the study of haplotype association with normal and CF chromosomes could be very helpful in cases where one or both mutations remain unidentified. In this study, we analysed with PCR-RFLP and capillary electrophoresis some extra (pJ3.11, KM19 and XV2C) and intragenic (IVS8CA, IVS17bTA and IVS17bCA) polymorphic markers in 50 normal and 10 Tunisian patients carrying the rare E1104X mutation in order to determine the haplotype associated with this mutation. For the extragenic markers, 8 haplotypes were identified. The most frequent of them are the 221 and 112 accounting for $80 \%$ of total haplotypes. For the intragenic markers, five haplotypes were present on the E1104X chromosomes. One of them 16-31-13 accounted for 50\%. To our knowledge, this is the first work to be interested to the haplotypes linked to the E1104X mutation. This preliminary study of haplotypes could be a helpful method to determine the molecular lesions responsible of this pathology.
\end{abstract}

Keywords: CF, E1104X mutation, haplotype, extragenic markers, intragenic mark

Cystic fibrosis (CF) is the most common lethal autosomal recessive disorder in Caucasian populations. The gene responsible for this disease, encodes a 1480 amino-acid protein called the cystic fibrosis transmembrane conductance regulator CFTR (13). Numerous mutations on this gene have been identified to be responsible for $\mathrm{CF}$.

The most common defect is observed to be the F508 del mutation, deletion of 3 base pair in exon 10. In Tunisian population, 12 different CFTR mutations, accounting for $90 \%$ of CF alleles, have been found. The E1104X located in exon 17b, is the second mutation after the F508del mutation in our population, represents $16.18 \%$ of all CF mutations but it is a rare mutation in the world (9).

In populations with heterogeneous spectrum mutations, genetic analysis can be facilitated by haplotype study.

The haplotypes associated with the CFTR mutations in the North African population remain unidentified. In this work we aimed to determine haplotypes associated with the E1104X mutation using 3 intragenic microsatellites (IVS8CA, IVS17bTA and IVS17bCA), and 3 extragenic markers (pJ3.11, KM19 and XV2C). The combination of both types of markers is expected to provide useful information regarding the origin and evolution of CFTR mutations (20).

Corresponding author: Pr. Taieb Messaoud

Biochemistry Laboratory, Research Laboratory "Haemoglobinopathies and Cystic Fibrosis, LROOSPO3", Children's

Hospital, Tunis, Tunisia

Phone: 21671 562521; Fax: 21671566 463; E-mail: taieb.messaoud@rns.tn 
Association of haplotype with a specific CFTR mutation would help to increase genetic informativity for prenatal diagnosis and carrier detection in many of studied families where one or no mutations are known.

\section{Materials and Methods}

This study included $10 \mathrm{CF}$ pediatric patients, aged between 2 and 18 months. The selection was based on typical clinical manifestations of pulmonary and/or gastro-intestinal disease and high levels of sweat chloride concentration (higher than $60 \mathrm{mmol} / \mathrm{l}$ ). The CFTR mutation was previously identified to be the E1104X mutation using DGGE and sequencing reaction (9).

A control group consisting of 50 healthy non-CF patients, aged between 2 months and 4 years, was also studied.

All CF children and healthy controls parents participating in this study were informed in details about the study and informed consents were signed.

Genomic DNA of studied samples was extracted from peripheral blood with the classical salting-out protocol (16).

\section{RFLP analysis}

Extragenic markers (pJ3.11, KM19 and XV2C) were analyzed with restriction fragment length polymorphism (RFLP) procedure.

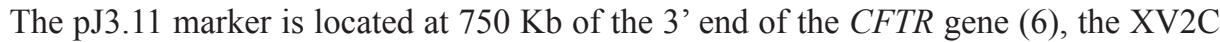
and KM19 markers are located 175 and $125 \mathrm{~Kb}$ up stream of the 5' end of the CFTR gene (22).

RFLP allows to discriminate between two alleles at each marker based on the presence or the absence of a restriction site.

DNA was amplified using sequence primers previously described. (Table I) $(6,22)$.

To analyze XV2C marker, the products were digested by TaqI restriction enzyme (22). For pJ3.11 and KM19 markers, amplified products were analyzed by PstI restriction enzyme $(14,22)$. PCR and restriction products were separated by electrophoresis on $2 \%$ agarose gel.

The extragenic haplotype construction was established using the standard nomenclature; the absence of the restriction site (-) corresponds to allele 1 , and the presence of the restriction $(+)$ site corresponds to allele $2(8)$.

Table I. Sequences of primers used in the study of extragenic and intragenic markers

\begin{tabular}{|l|l|l|l|l|}
\hline \multicolumn{2}{|c|}{ Extragenic markers } & \multicolumn{3}{c|}{ Intragenic markers } \\
\hline Markers & \multicolumn{1}{|c|}{ Sequences } & Markers & \multicolumn{1}{c|}{ Sequences } & Fluorochrome \\
\hline XV2C & $\begin{array}{l}\text { (F) 5'gttgaagtgaattgaatg3' } \\
\text { (R) 5'gttcaaactatgtcaaag3' }\end{array}$ & IVS8CA & $\begin{array}{l}\text { (F) 5'aaatctatctcatgttaatgctgaaga3' } \\
\text { (R) 5' actaagatatttgcccattatcaagtt3' }\end{array}$ & Fam \\
\hline KM19 & $\begin{array}{l}\text { (F) 5'gctgcatcatataagttgcc3' } \\
\text { (R) 5' 'aaggctacactgttaattt13' }\end{array}$ & IVS17bCA & $\begin{array}{l}\text { (F) 5'tgtcacctcttcatactcat 3' } \\
\text { (R) 5'aaacttaccgacaagaggaa 3' }\end{array}$ & Hex \\
\hline pJ3.11 & $\begin{array}{l}\text { (F) 5'ccactgatactgtgagac3' } \\
\text { (R) 5'gttgttcaagtcactgc 3' }\end{array}$ & IVS17bTA & $\begin{array}{l}\text { (F) 5' 'gctgcattctataggttatc3' } \\
\text { (R) 5'tgtgaaaacagggataatac3' }\end{array}$ & Fam \\
\hline
\end{tabular}




\section{Multiplex PCR}

Intragenic markers IVS8CA (intron8), IVS17bTA and IVS17bCA (intron 17b) were analyzed by a multiplex PCR reaction. PCR were performed with $200 \mathrm{ng}$ of DNA, 1X Master Mix (Promega) and 10 pmoles of each primer with fluorescent Hex or Fam phosphoramidites in a total volume of $14 \mu \mathrm{l}$.

The primer sequences was previously described (Table I) $(17,26)$.

\section{Capillary electrophoresis}

PCR with thirty-five cycles for 1 min each at $90{ }^{\circ} \mathrm{C}, 57{ }^{\circ} \mathrm{C}$ and $72{ }^{\circ} \mathrm{C}$ were performed. Amplified products $(1 \mu \mathrm{l})$ were mixed with $12 \mu \mathrm{l}$ deionised formamide and $1 \mu \mathrm{l}$ of 500 TAMRA Size standard (Applied Biosystems). Samples were denatured at $92{ }^{\circ} \mathrm{C}$ for $3 \mathrm{~min}$, then injected in ABI Prism 310 genetic analyzer (Applied Biosystems). Electrophoresis was performed in POP4polymer (Applied Biosystems), $15 \mathrm{Kv}$ with $5 \mathrm{~s}$ injection time and $30 \mathrm{~min}$ electrophoresis time on a $47 \mathrm{~cm} 50 \mu \mathrm{m}$ capillary (Applied Biosystems). After electrophoresis, fluorescence data was filtered and analysed using GeneScan analysis software version 3.1.2.

Each haplotype is named according to the number of repeats at loci IVS8CA, IVS17bTA and IVS17bca, respectively.

\section{Statistical analysis}

Chi-square test was used to compare the haplotype association among CF patients and healthy individuals.

\section{Results and Discussion}

The E1104X mutation, initially discovered by Zielenski in a French-Canadian patient in 1992 (http://www.genet.sickkids.on.ca/cftr/), consists of a single nucleotide substitution (G to T) at position 3442 in exon 17b, and causes introduction of a premature stop codon (GAA to TAA) at position 1104 in the protein sequence (27).

The E1104X mutation was later described in Germany by Reiss in 1993 (21), in France $(4,23,24)$, and in US (10).

This mutation is considered rare in the wordwide CF population but seems to be more frequent in our population with $16.18 \%$ of CF chromosomes (9).

The study of extragenic haplotypes associated with the E1104X allele revealed 8 different haplotypes (Table II). Five of them were found in CF chromosomes as well as in normal ones (Table II). The other three haplotypes were encountered solely in healthy individuals.

The 221 and 112 haplotypes accounting, respectively, for $45 \%$ and $35 \%$ of $\mathrm{CF}$ chromosomes haplotypes were significantly more frequent in this group than in healthy individuals ( $p=0.00019,0.006$ respectively) (Table II).

Analysis of intragenic haplotypes established with microsatellites markers IVS8CA, IVS17bTA and IVS17bCA are shown in Table III.

For the 120 analyzed chromosomes, 42 different haplotypes were described. Five haplotypes were observed in E1104X chromosomes. One of them (16-31-13), accounting for $50 \%$, was strongly associated to this mutation $\left(p=6.410^{-11}\right)$ (Table III). 
Table II. Different extragenic haplotypes found in the 120 analyzed chromosomes

\begin{tabular}{|c|c|c|c|c|c|}
\hline \multirow[t]{2}{*}{ Haplotype name } & \multicolumn{2}{|l|}{ E1104X mutation } & \multicolumn{2}{|l|}{ Normal } & \multirow{2}{*}{$P$} \\
\hline & Number of chromosomes & $\%$ & Number of chromosomes & $\%$ & \\
\hline 221 & 9 & 45 & 11 & 11 & 0.00019 \\
\hline 112 & 7 & 35 & 11 & 11 & 0.006 \\
\hline 111 & 2 & 10 & 21 & 21 & 0.253 \\
\hline 222 & 1 & 5 & 23 & 23 & 0.066 \\
\hline 211 & 1 & 5 & 8 & 8 & 0.641 \\
\hline 121 & \multicolumn{2}{|l|}{-} & 10 & 10 & \\
\hline 212 & \multicolumn{2}{|l|}{-} & 8 & 8 & \\
\hline 122 & \multicolumn{2}{|l|}{-} & 8 & 8 & \\
\hline Total & \multicolumn{2}{|l|}{20} & \multicolumn{2}{|l|}{100} & \\
\hline
\end{tabular}

Haplotype is named according to the absence (1) or presence (2) of restriction site at loci pJ3.11, KM19 and XV2C, respectively

A second haplotype (16-30-13) present only in CF chromosomes representing 20\% appears also to be highly associated with this mutation $(p=0.00038)$ (Table III). Two other less frequent haplotypes (16-30-14 and 16-29-14) show significant association with CF chromosomes ( $p=0.013$ and 0.018 respectively) (Table III).

The multiple allelism of CF prevents the rapid and reliable diagnosis of the diseasecausing mutations in compound heterozygotes and non-F508del homozygotes. Knowledge of the population genetics and the chromosomal marker haplotype of the various CFTR mutations would significantly facilitate the mutation diagnosis in $\mathrm{CF}$.

Microsatellites and single nucleotide polymorphisms (SNPs) have been described within the CFTR gene. Both types of markers can be used to trace the origin and evolution of the different CF mutations $(1,18,19,25)$. SNPs can be used to define the stable haplotypic frameworks on which CFTR mutations occurred. Microsatellite markers, which mutate faster and that are more diverse among chromosomes, can help to measure genetic variability within the CFTR locus and to estimate the age of CF mutations $(1,7,15,26)$.

The most common CF mutations (F508del, G542X and N1303K), provide an exceptional opportunity for the analysis of association between microsatellite allelic systems and SNP's. The patterns of haplotypes associated with these mutations should help in the understanding of the evolution of microsatellite loci and should help to define the anthropological time of the mutation (10). However, the haplotype analysis linked to rare mutation remains undetermined, that is why in this study we aimed to determine haplotypes associated with the E1104X mutation using some extra (pJ3.11, KM19 and XV2C) and intragenic (IVS8CA, IVS17bTA and IVS17bCA) polymorphic markers. We opted to combine six different markers for better informativity and for their strong association with CFTR gene (Fig. 1).

Our work is the first in the world to be interested to the study of the haplotype linked to the E1104X mutation. In fact, this mutation was observed in different populations from Canada, France, Germany and the US, with a low frequency excepted in Tunisian and Libyan populations where it represents $16.18 \%$ and $40 \%$, respectively, of CFTR spectrum mutation $(9,11)$. We found it interesting to determine haplotypes associated with the E1104X mutation to provide information on the age and origin of this mutation. 
Table III. Distribution of the microsatellites haplotypes among normal and CF chromosomes

\begin{tabular}{|c|c|c|c|c|c|}
\hline \multirow[t]{2}{*}{ Name of haplotype } & \multicolumn{2}{|l|}{ E1104X mutation } & \multicolumn{2}{|l|}{ Normal } & \multirow{2}{*}{$P$} \\
\hline & Number of chromosomes & $\%$ & Number of chromosomes & $\%$ & \\
\hline $16-31-13$ & 10 & 50 & 2 & 2 & $6.410^{-11}$ \\
\hline $16-30-13$ & 4 & 20 & - & - & 0.00038 \\
\hline $16-30-14$ & 2 & 10 & - & - & 0.013 \\
\hline $16-29-14$ & 2 & 10 & 1 & 1 & 0.018 \\
\hline $22-31-14$ & 2 & 10 & 4 & 4 & 0.261 \\
\hline $17-07-17$ & - & & 13 & 13 & \\
\hline $23-31-13$ & - & & 6 & 6 & \\
\hline $18-7-13$ & - & & 5 & 5 & \\
\hline $23-44-15$ & - & & 3 & 3 & \\
\hline $18-31-13$ & - & & 4 & 4 & \\
\hline $22-44-13$ & - & & 2 & 2 & \\
\hline $16-38-13$ & - & & 6 & 6 & \\
\hline $16-33-13$ & - & & 2 & 2 & \\
\hline $22-48-13$ & - & & 3 & 3 & \\
\hline $18-41-13$ & - & & 2 & 2 & \\
\hline $22-43-13$ & - & & 2 & 2 & \\
\hline $23-28-17$ & - & & 3 & 3 & \\
\hline $22-30-13$ & - & & 2 & 2 & \\
\hline $23-32-15$ & - & & 3 & 3 & \\
\hline $16-44-13$ & - & & 2 & 2 & \\
\hline $17-44-11$ & - & & 1 & 1 & \\
\hline $18-29-16$ & - & & 1 & 1 & \\
\hline $19-7-17$ & - & & 4 & 4 & \\
\hline $22-33-13$ & - & & 3 & 3 & \\
\hline $16-41-17$ & - & & 1 & 1 & \\
\hline $16-40-15$ & - & & 2 & 2 & \\
\hline $15-30-13$ & - & & 2 & 2 & \\
\hline $16-47-14$ & - & & 1 & 1 & \\
\hline $16-48-13$ & - & & 1 & 1 & \\
\hline $17-42-14$ & - & & 3 & 3 & \\
\hline $23-47-13$ & - & & 1 & 1 & \\
\hline $16-33-15$ & - & & 2 & 2 & \\
\hline $16-40-17$ & - & & 1 & 1 & \\
\hline $17-45-13$ & - & & 2 & 2 & \\
\hline $17-31-11$ & - & & 1 & 1 & \\
\hline $18-31-15$ & - & & 1 & 1 & \\
\hline $16-45-13$ & - & & 2 & 2 & \\
\hline $15-37-13$ & - & & 1 & 1 & \\
\hline $17-41-13$ & - & & 2 & 2 & \\
\hline $23-44-11$ & - & & 1 & 1 & \\
\hline $16-40-11$ & - & & 1 & 1 & \\
\hline $22-35-17$ & - & & 1 & 1 & \\
\hline
\end{tabular}

Each haplotype is named according to the number of repeats at loci IVS8CA, IVS17bTA and IVS17bCA, respectively 


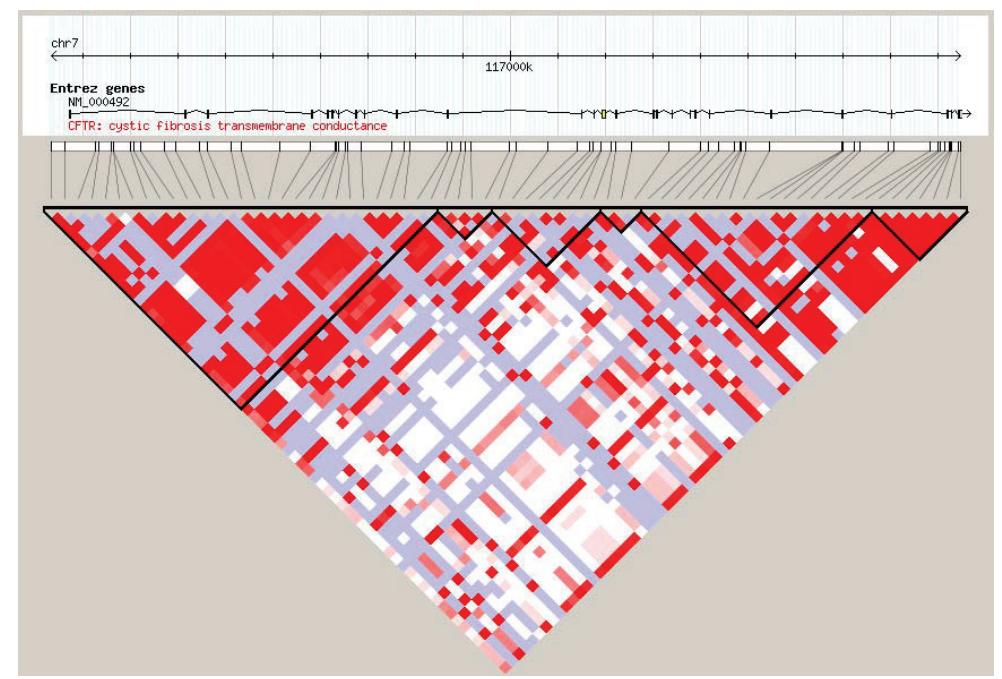

Fig. 1. Linkage Disequilibrium (LD) Plot of the CFTR gene from the Haploview software 4.2.

Schematic diagram of the CFTR gene on chromosome 7. Exons are represented by vertical lines or Boxes. The diamond color indicates the level of LD; darker shades indicate a higher LD while lighter shades indicate lower LD and Grey regions represent missing data points

Statistical analysis showed difference between haplotypes distribution in normal and CF chromosomes. For the extragenic haplotype, E1104X mutation is associated in $80 \%$ of cases to both 221 and 112 haplotypes. However, these two haplotypes were observed only in $20 \%$ of normal population chromosomes ( $p=0.00019,0.006$, respectively) (Table II).

The E1104X mutation revealed a heterogeneous microsatellite polymorphism profile since it was associated with five different haplotypes. The most frequent microsatellites haplotype 16-31-13 is found only in one chromosome of normal population $\left(p=6.410^{-11}\right)$ (Table III). This association can help considerably in mutation analysis by using microsatellite markers after screening for F508del.

The 16-31-13 haplotype found in 50\% of E1104X chromosomes was also described linked to 2 rare mutations, the E60X mutation in UK (12) and S549N mutation in the "Grande briére" population (3). Association of the same haplotype with these 3 mutations suggest a common origin.

The 23-31-13 haplotype generally associated with the most common mutation F508del $(2,5)$, was not encountered in the E1104X chromosomes. However, the similarity on the IVS17bTA and IVS17bCA markers between this haplotype and the 16-31-13 haplotype would also suggest a common ancestral genetic background on which both mutations arose.

On the other hand, the 16-30-13 and 16-30-14 haplotypes not observed in the normal chromosomes could be suggested as specific and sensitive haplotypes for E1104X mutation.

The 16-30-13, 16-30-14 and 16-29-14 haplotypes seem to derive from the 16-31-13 one as a result of a slippage at the IVS17bTA and/or IVS17bCA markers which thus suggesting a fonder effect.

In our country $9.56 \%$ of CFTR mutations remain indetermined (27). In this case a combination of methods for mutation detection and haplotype analysis could provide rapid, accurate, and reliable information especially in prenatal diagnosis for couples at risk of having a child affected with cystic fibrosis. 
This first preliminary study of haploypes linked to E1104X mutation can be completed by the analysis of a large sample of patients with E1104X mutation and other mutations found in Tunisia.

Knowledge of CFTR mutation haplotypes in our population would significantly facilitate mutation diagnosis.

\section{REFERENCES}

1. Bertranpetit J, Calafell F: Genetic and geographical variability in cystic fibrosis: evolutionary considerations. Ciba. Found. Symp. 197-114 (1996)

2. Claustres M, Desgeorges M, Moine P, Morral N, Estivill X: CFTR haplotypic variability for normal and mutant genes in cystic fibrosis families from southern France. Hum. Genet. 98, 336-344 (1996)

3. De Braekeleer M, Chaventré A, Bertorelle G, Verlingue C, Raguénès O, Mercier B, Férec C: Linkage disequilibrium between the four most commun cystic fibrosis mutations and microsatellite haplotypes in the Celtic population of Brittany. Hum. Genet. 98, 223-227 (1996)

4. Des Georges M, Guittard C, Altiéri JP, Templin C, Sarles J, Sarda P, Claustres M: High heterogeneity of CFTR mutations and unexpected low incidence of cystic fibrosis in the Mediterranean France. J. Cyst. Fibros. 3, $265-272(2004)$

5. Elce A, Boccia A, Cardillo G, Giordano S, Tomaiuolo R, Paolella G, Castaldo G: Three novel CFTR polymorphic repeats improve segregation analysis for cystic fibrosis. Clin. Chem. 55, 1372-1379 (2009)

6. Estivill X, McLean C, Nunes V, Casals T, Gallano P, Scambler P, Williamson R: Isolation of a new DNA marker in linkage disequilibrium with cystic fibrosis, situated between J3.11 (D7S8) and IRP. Am. J. Hum. Genet. 44, 704-710 (1989)

7. Estivill X, Morral N, Bertranpetit J: Age of the DF508 cystic fibrosis mutation. Nat. Genet. 8, 216-218 (1994)

8. Flores-Martínez SE, Martínez JF, Machorro-Lazo MV, García-Zapién AG, Salgado-Goytia L, Cruz-Quevedo EG, Morán-Moguel MC, Sánchez-Corona J: XV-2c/KM19 haplotypes analysis of cystic fibrosis patients from western Mexico. Acta Physiol. Hung. 95, 313-325 (2008)

9. Fredj SH, Messaoud T, Templin C, des Georges M, Fattoum S, Claustres M: Cystic fibrosis transmembrane conductance regulator mutation spectrum in patients with cystic fibrosis in Tunisia. Genet. Test. Mol. Biomarkers. 13, 577-581 (2009)

10. Green DM, McDougal KE, Blackman SM, Sosnay PR, Henderson LB, Naughton KM, Collaco JM, Cutting GR: Mutations that permit residual CFTR function delay acquisition of multiple respiratory pathogens in CF patients. Respir. Res. 11, 140-148 (2010)

11. Hadj Fredj S, Fattoum S, Chabchoub A, Messaoud T: First report of cystic fibrosis mutations in Libyan cystic fibrosis patients. Ann. Hum. Biol. 38, 561-563 (2011)

12. Hughes D, Wallace A, Taylor J, Tassabehji M, McMahon R, Hill A, Nevin N, Graham C: Fluorescent multiplex microsatellites used to define haplotypes associated with 75 CFTR mutations from the UK on 437 CF chromosomes. Hum. Mutat. 8, 229-235 (1996)

13. Kerem B, Rommens JM, Buchanan JA, Markiewicz D, Cox TK, Chakravarti A, Buchwald M, Tsui LC: Identification of cystic fibrosis gene: genetic analysis. Science 245, 1073-1080 (1989)

14. Lathrop GM, Farrall M, O’Connell P, Wainwright B, Leppert M, Nakamura Y, Lench N, Kruyer H, Dean M, Park M, Vande Woude G, Lalouel JM, Williamson R, White R: Refined linkage map of chromosome 7 in the region of the cystic fibrosis gene. Am. J. Hum. Genet. 42, 38-44 (1988)

15. Mateu E, Calafell F, Ramos MD, Casals T, Bertranpetit J: Can a place of origin of the main cystic fibrosis mutations be identified?. Am. J. Hum. Genet. 70, 257-264 (2002)

16. Miller SA, Dykes DD, Polesky HF: A simple salting-out for extracting DNA from human nucleated cells. Nucleic Acids Res. 16, 1215 (1988)

17. Morral N, Nunes V, Casals T, Estivill X: CA/GT microsatellite alleles within the cystic fibrosis transmembrane conductance regulator (CFTR) gene are not generated by unequal crossingover. Genomics 10, 692-698 (1991)

18. Morral N, Nunes V, Casals T, Chillón M, Giménez J, Bertranpetit J, Estivill X: Microsatellite haplotypes for cystic fibrosis: mutation frameworks and evolutionary tracers. Hum. Mol. Genet. 2, 1015-1022 (1993)

19. Morral N, Bertranpetit J, Estivill X, Nunes V, Casals T, Giménez J, Reis A, Varon-Mateeva R, Macek Jr. M, Kalaydjieva L, Angelicheva D, Dancheva R, Romeo G, Russo MP, Garnerone S, Restagno G, Ferrari M, Magnani C, Claustres M, Desgeorges M, Schwartz M, Schwarz M, Dallapiccola B, Novelli G, Ferec C, De Arce M, Nemeti M, Kere J, Anvret M, Dahl N, Kadasi L: The origin of the major cystic fibrosis mutation (DF508) in European populations. Nat. Genet. 7, 169-175 (1994) 
20. Morral N, Dörk T, Llevadot R, Dziadek V, Mercier B, Férec C, Costes B, Girodon E, Zielenski J, Tsui LC, Tümmler B, Estivill X : Haplotype analysis of 94 cystic fibrosis mutations with seven polymorphic CFTR DNA markers. Hum. Mutat. 8, 149-159 (1996)

21. Reiss J, Ellermeyer U, Rininsland F, Ballhausen P, Lenz U, Wagner S, Schlösser M: A comprehensive CFTR mutation analysis of German cystic fibrosis patients. Hum. Mol. Genet. 2, 809-811 (1993)

22. Repetto MR, Puga AR, Delgado I: XV-2c and KM.19 haplotype analysis in Chilean patients with cystic fibrosis and unknown CFTR gene mutations. Biol. Res. 40, 223-229 (2007)

23. Scotet V, Barton DE, Watson JB, Audrézet MP, McDevitt T, McQuaid S, Shortt C, De Braekeleer M, Férec C, Le Maréchal C: Comparison of the CFTR mutation spectrum in three cohorts of patients of celtic origin from Brittany (France) and Ireland. Hum. Mutat. 22, 105-115 (2003)

24. Sermet-Gaudelus I, Boeck KD, Casimir GJ, Vermeulen F, Leal T, Mogenet A, Roussel D, Fritsch J, Hanssens L, Hirawat S, Miller NL, Constantine S, Reha A, Ajayi T, Elfring GL, Miller LL: Ataluren (PTC124) induces cystic fibrosis transmembrane conductance regulator protein expression and activity in children with nonsense mutation cystic fibrosis. Am. J. Respir. Crit Care Med.182, 1262-1272 (2010)

25. Slatkin M, Rannala B: Estimating the age of alleles by use of intraallelic variability. Am. J. Hum. Genet. 60 , 447-458 (1997)

26. Zielenski J, Markiewicz D, Rininsland F, Rommens J, Tsui LC: A cluster of highly polymorphic dinucleotide repeats in intron $17 \mathrm{~b}$ of the cystic fibrosis transmembrane conductance regulator (CFTR) gene. Am. J. Hum. Genet. 49, 1256-1262 (1991)

27. Zielenski J, Markiewicz D, Chen HS, Schappert K, Seller A, Durie P, Corey M, Tsui LC: Identification of six mutations (R31L, 441delA, 681delC, 1461ins4, W1089R, E1104X) in the cystic fibrosis transmembrane conductance regulator (CFTR) gene. Hum. Mutat. 5, 43-47 (1995) 